\title{
The level of awareness and use of anticoccidials in poultry farms in South Western Nigeria
}

\author{
R. O. A. Arowolo ${ }^{1 \star}$, K. O. Soetan ${ }^{1}$, O. O. Arowolo ${ }^{2}$ and O. O. Sodimu ${ }^{1}$ \\ ${ }^{1}$ Department of Veterinary Physiology, Biochemistry and Pharmacology, University of Ibadan, Nigeria. \\ ${ }^{2}$ Department of Agricultural Extension and Rural Development, Federal University of Agriculture Abeokuta (FUNAAB), \\ Abeokuta, Ogun State. \\ Accepted 1 October, 2012
}

This study investigated the level of awareness and usage of anticoccidial drugs and vaccines by poultry farms in southwestern geopolitical zones of Nigeria, using Lagos, Oyo, and Ogun states. A researcher-made questionnaire was administered to the selected poultry farms, poultry attendants and veterinarians. With the deduction of an attrition value of $10 \%$ on questionnaire retrieval, data from 72 respondents out of 80 administered were used for statistical analysis. Information was obtained on the mode of administration, treatment programming strategy as well as the poultry farmers' awareness and usage of the anticoccidial agents (drugs and vaccines). The result of the study shows that most of the poultry (69.6\%) farms are aware of and used anticoccidial drugs like amprolium, clopidol, chlortetracycline and oxytetracycline. $77.8 \%$ are also aware of anticoccidial vaccines like paracox, livacox, coccivac and immucox with only $59.6 \%$ of the farmers already using it. Adverse effects of anticoccidials were observed on very rare occasions.

Key words: Pharmacoepidemiology, anticoccidials, coccidiosis, poultry.

\section{INTRODUCTION}

Pharmacoepidemiology is the study of the use and effects of drugs in livestock and humans (Strom, 2000). It is a relatively new field which could readily assist policy makers in making regulatory decisions about approving a drug for marketing or for clinical decisions when presenting the drug for use.

Coccidiosis is a disease of fowls caused by microscopic protozoa, mainly Eimeria species, and it is characterized by diarrhea, unthriftiness and variable levels of mortality (Ademola, 2006). All livestock species such as birds, cattle, sheep, pigs, rabbits and even wild animals such as grass cutters can be infected with coccidiosis, but it is more prevalent in poultry raised in large numbers in an intensive management system, especially when kept on deep litter. Extensively managed birds (that is, those on range or kept as outdoor flocks) could also be infected.

\footnotetext{
*Corresponding author. E-mail: roa_arowolo@hotmail.com.
}

The disease is characterized by the invasion of the intestinal wall with the parasite resulting in damage to the mucosal and sub-mucosal tissues, thus resulting in haemorrhage and subsequent mortality in an unprotected poultry flock. Although, coccidiosis has been reported in cattle, sheep, pigs, rabbits, etc. It has been found to cause the most devastating losses in poultry. Long (1993) reported that an estimated 350 million US dollars are spent worldwide and 80 million US dollars in the United States on anticoccidial. He further posited that the economic importance of this poultry disease is reflected by the voluminous publications (about 2,000) on the chemotherapy of coccidial infection. Most of these studies examined avian coccidiosis and the availability of about 154 anticoccidial products for the treatment and prevention of coccidiosis as far back as 1991 (Shepard et al., 1991). However, the current awareness and utility of some of these anticoccidial products has not yet been thoroughly examined in Nigeria.

Therefore, the present survey study was designed to assess the level of awareness and use of anticoccidial drugs (chemicals) and vaccines by the South Western 
Nigerian poultry farms. Investigators collated and analyzed data obtained on anticoccidials commonly used for the prevention and treatment of coccidiosis in these farms. The study also examined modes of administration, types of administration programming used, and the perception of the poultry farmers on the efficacy and the effect of the treatments (adverse or non-beneficial) on the birds.

Poultry farms in the southwestern geographical zone of Nigeria, primarily in Lagos, Ogun and Oyo states were included in the study. Results from this study will: (1) enable poultry farmers, poultry attendants, animal scientists, livestock extension agents and veterinary doctors to answer basic questions that may arise from time to time on the use of these drugs or vaccines on the poultry farms, (2) provide additional knowledge on the therapeutic benefits and the adverse effects of anticoccidials in poultry birds, and (3) provide a better understanding of the two medications (anticoccidial drugs or vaccines) and determine which treatment is more efficacious in the control of avian coccidiosis.

\section{Study objectives}

This study specifically set out to (1) describe the demographic or socio-economic characteristics of the poultry farms in Lagos, Ogun and Oyo states, (2) examine the system of management adopted by these farms, (3) examine the level of their awareness and usage of anticoccidial drugs and anticoccidial vaccines, and (4) relate the level of awareness on anticoccidial drugs to the farmers' level (scale) of production and discuss the efficacy of the treatments.

\section{METHODOLOGY}

The sample frame for this survey study included poultry farms, stakeholders of the poultry industries (feed mills, veterinary doctors, poultry attendants, etc) in Lagos, Oyo and Ogun states in the South Western Nigeria.

The instrument used for the study was a researcher-made questionnaire consisting of 22 items: (1) name of the farm, (2) address of the farm, (3) age of farm, (4) incidence of coccidiosis on the farm, (5) types of anticoccidials used (drugs or vaccines), (6) mode of administration of treatment, (7) efficacy of anticoccidials, are reared on the farm, (10) age at which the administration of the anticoccidials commence, (11) frequency of administration of the anticoccidials, etc. The questionnaires were personally administered by the researchers and trained assistants to 80 respondents and the completed questionnaires were retrieved thereafter. However, a low attrition value of $10 \%$ was encountered with the 80 questionnaires distributed. This implied that only 72 of the respondents' questionnaires were available for final analysis $(\mathrm{N}$ =72). The attrition value was low and regarded as insignificant; hence, the instrument is acceptable for use. Additionally, the problem of relying on responses given from memory was encountered with some farms, because of lack of proper record keeping. Data obtained from this survey were statistically analyzed using descriptive statistics such as mean, frequency, percentage and charts and using Statistical Package for Social Sciences (SPSS) for inferential statistics.

\section{RESULTS AND DISCUSSION}

The demographic characteristics of the 72 poultry farms surveyed for their awareness and use of anticoccidial drugs are summarized in Tables 1 to 3 .

Table 1 shows that majority $(43.1 \%)$ of the poultry farmers in Lagos, Ogun and Oyo states are small scale farmers with flock size of 501 to 2,000 birds, while $19.4 \%$ are medium scale farmers with 2,001 to 10,000 birds. The large scale poultry farmers with 10,001 to 50,000 and greater than 100,000 birds constitute 8.3 and $2.8 \%$, respectively. The bar chart in Figure 1 shows that the highest proportion (44.4\%) of these poultry farmers keep solely layers, while a scanty proportion of $4.2 \%$ keep either broilers or breeders only.

Figure 1 illustrates that $22.2 \%$ were in favour of spreading their production efforts on all, by keeping the mixture of the three types of the birds (that is layers, broilers, and cockerels) together on the farm. Approximately $40 \%$ of the poultry farms visited had only been in existence for 5 to 10 years. The oldest poultry farms had existed for 16 to 30 years or longer and they were found to be either government owned or individual, private farms. These older farms constituted $12.5 \%$ of the farm population in the three states studied.

Table 2 revealed that the birds are mostly reared on deep litter system by $51.7 \%$ of the poultry farms. However, $23.6 \%$ of the farmers adopted the cage system of management, while the combination of both management systems was carried out by another $23.6 \%$ of the farms. Although, a greater proportion of the farmers (51.7\%) kept layers on litter, it is probably more efficient to raise egg laying birds in cages.

Although, $44.4 \%$ of the farms stated that they have never experienced an outbreak of coccidiosis, the management system and scale of production adopted could have been responsible for the $55.6 \%$ of the farms which indicated that they have experienced outbreak of coccidiosis. This high percentage $(55.6 \%)$ case of coccidial outbreaks may indicate that the management practices adopted by most of the poultry farms are inadequate for preventing coccidial outbreaks on these farms.

Table 3 indicates that the poultry farmers are aware of and used anticoccidial drugs. $30.6 \%$ of the farmers used the drugs prophylactically, $22.2 \%$ used the drugs for curative purpose, while $29.2 \%$ employed them for both purposes.

An almost equal percentage usage for both curative and prophylactic purpose obtained could be indicative of the commonness of the disease outbreak. Anticoccidials are broadly classified into chemicals and ionophores. The anticoccidial drugs which are broadly classified into chemicals are amprolium, clopidol and folic acid antagonists, while ionophores include lasalocids and narasin. These are the anticoccidials mostly used by these farms as shown in Table 2.

Figure 2 shows that $54.2 \%$ of the poultry farms used 
Table 1. Demographic characteristics of the poultry farmers studied in Lagos, Oyo, and Ogun States.

\begin{tabular}{lll}
\hline Distribution of respondents' characteristic & Frequency (f) & Percentage (\%) \\
\hline Farms' age range & 28 & 38.9 \\
Less than 5 years & 29 & 40.3 \\
$5-10$ years & 04 & 5.6 \\
$11-15$ years & 07 & 9.7 \\
$16-30$ years & 02 & 2.8 \\
Greater than 30 years & & \\
& & \\
Types of birds kept & 03 & 4.2 \\
Keeps broilers only & 32 & 44.2 \\
Keeps layers only & 03 & 04.2 \\
Keeps cockerels (only) for breeding & 18 & 25.0 \\
Keeps any two of the above & 16 & 22.2 \\
Keeps mixture of the three & & \\
& & \\
Type of farm & 36 & 50 \\
Keeps poultry farm only & 36 & 50 \\
Keeps poultry farm and some other livestock & & \\
& & \\
Farm size: Size of flock & 18 & 25.0 \\
Less than 500 birds & 20 & 27.8 \\
501 - 1,000 birds & 11 & $15.3(43.1 \%)$ \\
1,001 - 2,000 birds & 07 & 09.7 \\
2,001 - 5,000 birds & 07 & $09.7(19.4 \%)$ \\
5,001 - 10,000 birds & 06 & 08.3 \\
10,001 - 50,000 birds & 02 & 02.8 \\
More than 100,000 birds & & \\
\hline
\end{tabular}

Source: Survey Data.

Table 2. Incidence of coccidiosis and patronage of veterinary services by poultry farmers in the study areas $(\mathrm{N}=72)$.

\begin{tabular}{lll}
\hline Variable & Frequency (f) & Percentage (\%) \\
\hline Management system used & & \\
\hline Cage system only & 17 & 23.6 \\
Deep litter system only & 37 & 51.4 \\
Cage + deep litter systems & 17 & 23.6 \\
& & \\
Incidence of outbreak of coccidiosis & & \\
Experienced outbreak & 40 & 55.6 \\
No outbreak experienced & 32 & 44.4 \\
& & \\
Patronage of veterinary services & & \\
Full-time veterinary service & 15 & 20.8 \\
Part-time veterinary service & 45 & 62.5 \\
Full + part time veterinary service & 04 & 05.6 \\
No veterinary services & 07 & 09.7 \\
\hline
\end{tabular}

Source: Survey Data. 
Table 3. Anticoccidial drug usage by the poultry farms in Lagos, Ogun, and Oyo states.

\begin{tabular}{|c|c|c|}
\hline Anticoccidial drugs usage & Frequency (f) & Percentage (\%) \\
\hline \multicolumn{3}{|l|}{ Type of anticoccidial } \\
\hline Chemicals: amprolium, clopidol, folic acid antagonist & 39 & 54.2 \\
\hline Ionophores: lasalocid (Avatec), maduramycin, narasin, etc. & 08 & 11.2 \\
\hline Chemicals + ionophores & 03 & 04.2 \\
\hline No response & 22 & 30.6 \\
\hline \multicolumn{3}{|l|}{ Purpose of use of the drug } \\
\hline For prophylaxis & 22 & 30.6 \\
\hline For curative & 16 & 22.2 \\
\hline Curative + prophylaxis & 21 & 29.2 \\
\hline No response & 13 & 18.0 \\
\hline \multicolumn{3}{|l|}{ Mode of administration of the drug } \\
\hline Addition to water & 46 & 63.9 \\
\hline Addition to feed & 03 & 04.2 \\
\hline Addition to water + feed & 13 & 18.0 \\
\hline No response & 10 & 13.9 \\
\hline \multicolumn{3}{|l|}{ Mode of usage (combined or non combined) } \\
\hline Anticoccidial only & 25 & 34.7 \\
\hline Anticoccidial + vitamins & 11 & 15.3 \\
\hline Anticoccidial + antibiotics & 09 & 12.5 \\
\hline Not specific/no response & 27 & 37.5 \\
\hline \multicolumn{3}{|l|}{ Efficacy of anticoccidial drugs } \\
\hline Very effective & 27 & 37.5 \\
\hline Effective & 19 & 26.4 \\
\hline Very good & 04 & 05.6 \\
\hline Good & 07 & 09.7 \\
\hline Fair & 05 & 06.9 \\
\hline No response & 10 & 13.9 \\
\hline \multicolumn{3}{|l|}{ Adverse effects of anticoccidial drugs } \\
\hline Farms that consider it as having adverse effect on their birds & 10 & 13.9 \\
\hline Farms that say they do not have adverse effect on their birds & 44 & 61.1 \\
\hline No response & 18 & 25.0 \\
\hline
\end{tabular}

Source: Survey Data.

chemical anticoccidials, $11.2 \%$ use ionophores, while $4.2 \%$ used both of them (chemicals and ionophores). $30.6 \%$ of the respondents did not provide this information, either because they had no accurate records of disease management programmes or anticoccidial usage on the farm or could not recollect from memory at the time of the survey. Some farmers stated that they do not believe in or use anticoccidial drugs. The mode of action of ionophores is related to their ability to form lipophilic complexes with alkali metal cations and to transport these cations across biological membranes. lonophores differ in their affinities for cations. According to Zhu and McDougald (1992), Long and Jeffers (1982) and Smith et al. (1981), the ionophores that have anticoccidial activities act against extracellular sporozoites and merozoites, while Smith and Strout(1980) opined that they act against intracellular sporozoites and possibly gametogenous stages (Long and Jeffers, 1982). Chapman (1993) and Zhu and MacDougald (1992) all postulated that resistance to ionophores in poultry birds rarely occur in the field perhaps because the ionophores uniquely permit a small leakage of the coccidial to enable the birds to develop a certain level of immunity. The use of ionophores allows a 


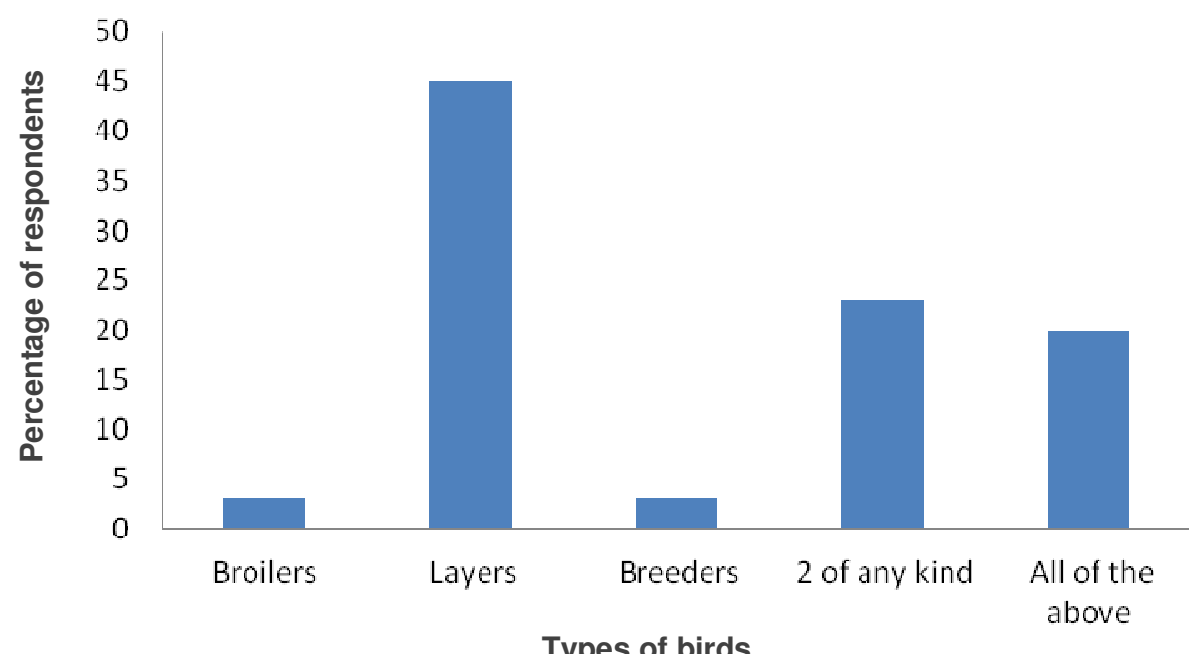

Figure 1. Bar chart showing the type of birds kept.

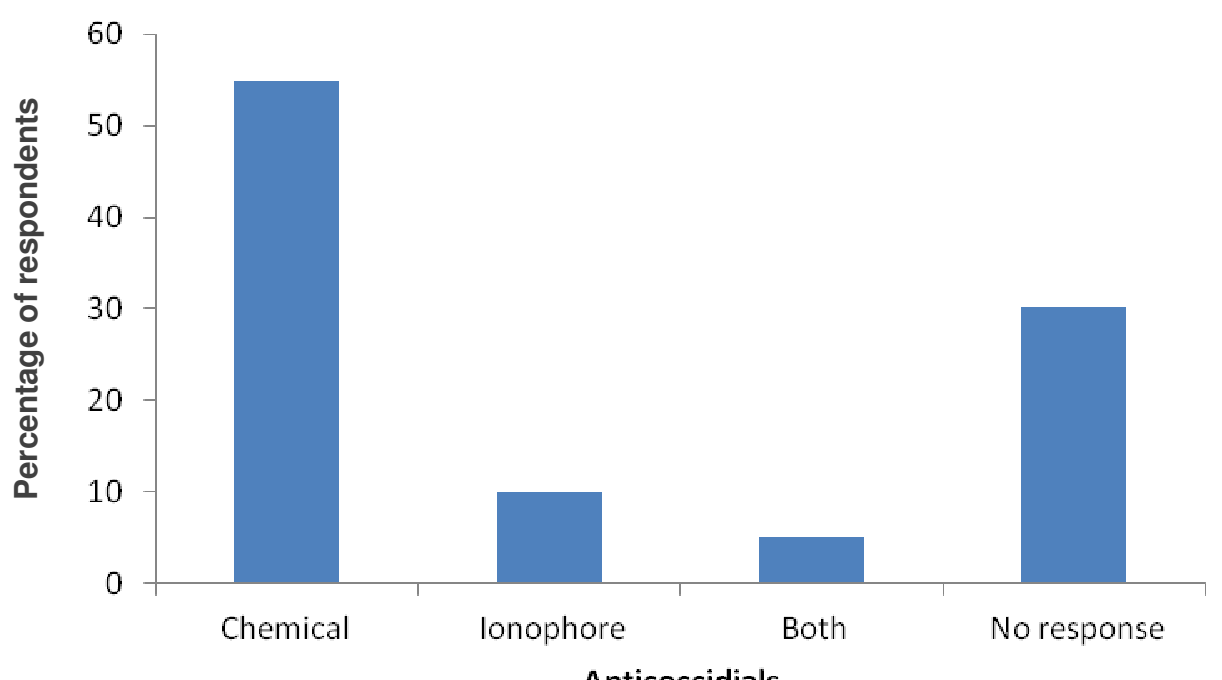

Figure 2. Bar chart illustrating the types of anticoccidials in use by the farms studied.

greater degree of protection against the parasite and is a much more efficient method of control. Merck Veterinary Manual CD ROM (2000) provides a comprehensive list of the anticoccidial drugs which can be used on poultry farms and the concentration of the product that may be added to the feed.

Most $(63.9 \%)$ of the poultry farmers are aware that it is preferable and more economical to administer anticoccidial drugs via addition to the drinking water for the birds on a bimonthly basis (that is, forthnightly). Administration of the drugs in water was preferable, because of the ease of administration, nevertheless, $4.2 \%$ of the farms opted for administering the drugs in the feed. The combination of anticoccidials and antibiotics was favoured by $12.5 \%$ of the poultry farms, while $15 \%$ use it in combination with vitamins. Approximately $60.0 \%$ of the poultry farms reported that this mode of drug administration was efficacious, because they did not experience any adverse after-effect when used.

Although, $77.8 \%$ of the poultry farmers in the study indicated that they are aware of the availability and use of anticoccidial vaccines for treating coccidiosis in birds, $56.9 \%$ of the poultry farmers admitted that they have never used anticoccidial vaccines on their birds, while a proportion as low as $43.1 \%$ have used them. These latter groups of poultry farmers are large scale farmers who consider vaccine usage as more effective or efficacious than the use of anticoccidial drugs. $36.1 \%$ of the farms in this study (Table 4) also corroborate this by finding that the use of anticoccidial vaccine is more effective. These farmers therefore settled more for vaccine application than drugs usage. The most favoured anticoccidial 
Table 4. Level of awareness of availability and use of anticoccidial vaccines by poultry farmers in Lagos, Ogun and Oyo states.

\begin{tabular}{lll}
\hline Variable & Frequency (f) & Percentage (\%) \\
\hline (a) Awareness of anticoccidial vaccines & & \\
Farmers that are aware & 56 & 77.8 \\
Farmers that are not aware & 16 & 22.2 \\
& & \\
(b) Usage of the anticoccidial vaccines & 31 & 43.1 \\
Have used the vaccine & 41 & 56.9 \\
Have never used the vaccine & & \\
& & 36.1 \\
(c) Comparison of use of anticoccidial drugs with vaccine & 26 & 04.2 \\
More effective & 03 & 01.4 \\
Less effective & 01 & 58.3 \\
Equal in efficacy & 42 & \\
No response &
\end{tabular}

Source: Survey Data.

vaccines are immunocox used in $22.2 \%$ of the farms, and livacox used by $6.9 \%$ of the farms. Some farms use either of the two interchangeably. Although, occasional occurrence of gout and retarded growth were reported experiences of some of the poultry farmers who use Embazine Forte(R) as anticoccidial drug, the judgmental report of a large proportion of the respondents or poultry farmers is that the drugs were very efficacious. $36.1 \%$ of the poultry farms studied also affirmed that anticoccidial vaccines were more efficacious than drugs but there could be constraints of cost and affordability.

\section{Conclusion}

Anticoccidial drugs and vaccines may be used on poultry farms to control and prevent coccidiosis. However, it is very important that hygienic practices be maintained on poultry farms for maximum efficacy. Veterinary practice and the provision of extension services in poultry production still need to be improved upon in Nigeria. This should involve the regular utilization of well informed extension workers and subject matter specialists (SMS), in collaboration with veterinarians, to give awareness and counseling talks on the benefits of usage of anticoccidial drugs and administration of anticoccidial vaccine to the farmers at the village or cell level. Such actions will enhance poultry production and boost the national economy.

It is recommended based on the findings of this survey that:

1) All poultry farmers should have at least a part-time veterinarian and a full or part-time extension staff or SMS registered with or in the employment of the zonal Agricultural Development Programme (ADP) arm of the state to ensure that anticoccidial drugs are administered properly.

2) All poultry farms should also engage the services of the Village Extension Agents (VEAs) and the Block Extension Agents (BEAs) in their vicinities.

3) Veterinarians should be invited to the Monthly Technological Review Meetings (MTRM) of the extension

workers and the SMS, where they could sensitize them on the benefits of using anticoccidial drugs and vaccines in poultry birds.

4) Seminars and conferences should be conducted jointly and regularly for poultry farmers, livestock extension agents and veterinarians on programmes available for the use of anticoccidial drugs.

5) More recognition should be given to livestock extension services than what is currently practiced. At the present time, livestock extension services are almost subsumed by the agronomic extension work.

6) Registration of all poultry farms with the appropriate authorities should be enforced and avenue for diseases reporting encouraged.

7) Survey on the use of anticoccidial drugs and vaccines should be conducted regularly by authorized government agency and the manufacturers so as to be able to detect and determine their efficacy, resistance and toxicity on the field with the view of identifying those that needed to be withdrawn from the market and to be replaced by new ones.

\section{REFERENCES}

Ademola IO (2006). Control strategies against Avian Coccidiosis. A Review. ASSET Series B 5(1):9-16.

Chapman HD (1993). Twenty-one years of Monensin for the control of Coccidiosis. A Review in the Proceedings of the $6^{\text {th }}$ International Coccid Conference, Guelph, Canada.

Long PL, Jeffers TK (1982). Studies on the stage of action of Ionophorous antibiotics against Eimeria. J. Parasitol. 68: 363-371.

Long PL (1993). Avian Coccidiosis. In: S.P. Kreier Ed. Parasitic

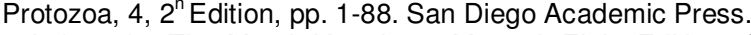

Merck (2000). The Merck Veterinary Manual, Eight Edition, CD ROM 2000. Merck and Co. Inc. 
Shepard ML, Carr PW, Loomis VM (1991). The complete handbook of new animal drug applications in the United States. Dallas: Shortwell and Carr.

Smith CK, Galloway RB, White SL (1981). Effects of lonophores on survival, penetration and development of Eimeria tenella sporozoites in - vitro. J. Parasitol. 67:511-516.

Smith CK, Strout RG (1980). E. tenella: Effect of Narasin, a polyether antibiotic on the ultrastructure of intracellular sporozoites. Experimental Parasitol. 50:426-436.

Strom BL (2000). What is Pharmacoepidemiology? In: Pharmacoepidemiology. $3^{\text {rd }}$ edition by B.L. Strom. John Wiley and Sons Ltd. England. p 3.
Zhu G, McDougald LR (1992). Characterization of in-vitro and in-vivo Resistance to lonophores in a strain of $E$. tenella. J. Parasitol.78:1067-1073. 